\title{
THE SELECTION OF RANDOM MOVEMENTS AS A FACTOR IN PHOTOTAXIS.'
}

\author{
By S. J. Holmes.
}

Contributions from the Zoological Laboratory of the Lniatrity of Wichisan, No. 91 .

It is customary to explain the phototactic movements of organisms as dependent upon a sort of forced orientation which is brought about by the fact that when the two sides of the body are stimulated unequally they give unequal muscular responses which result in turning the animal until both sides are stimulated to the same degree, when the creature moves either towards or away from the light in the direction of the rays. But however satisfactory this explanation may be for the photo. tactic movements of most organisms, there are several cases where locomotion is directed by the rays of light which cannot be accounted for in this way. It is well known that earthworms, leeches, and the larvæ of house-flies, blow-flies and many other insects have a strong tendency to shun the light and collect in the darkest regions they can reach. 'These forms have been cited as affording typical illustrations of negative phototaxis. The often precise orientation of these organisms to the direction of the rays very naturally disposes one to explain their phototactic movements as taking place according to the scheme just mentioned. No one has attempted to work out in detail the exact mode of response in any of these forms, although the fact of their orientation to the direction of the rays of light has been described by several different observers. A variety of explanations may be offered according to the gener-

\footnotetext{
1 The descriptive part of this paper with the exception of a few minor changes was read before the section of Animal Morphology of the International Congress of Arts and Sciences at St. Louis, Mo., Sept. 21 , 1904.
} 
al theory we have referred to. It might be assumed, in the earthworm, for instance, that light causes a greater contraction of the longitudinal muscles on the less illuminated side, or that it inhibits the action of the longitudinal muscles on the side that receives the greater stimulus, or that both these effects are combined. The attempt was made to get some clue to the method of orientation by carefully watching the movements of the animals under the influence of light. It soon developed that what seemed at first a forced orientation, the result of a direct reflex response, is not really such, but that the orientation which occurs and which is often quite definite is brought about in a more indirect manner by a mode of procedure which is in some respects similar to the method of trial and error followed by higher forms.

The response of the earthworm to light has been noted by several observers Hofmeister, ${ }^{1}$ Darwin, ${ }^{2}$ Graber. ${ }^{3}$ Yung, Hesse, ${ }^{5}$ Parker and Arkin, ${ }^{6}$ Smith. ${ }^{7}$ and Adams. ${ }^{8}$ While all parts of the surface of the earthworm are sensitive to light the directive influence of light, as PARKer and AkKin have shown, is greatest at the anterior end of the body and diminishes towards the posterior end. The negative reaction of the earthworm becomes less as the intensity of the light is diminished, and in very weak light the reaction, according to Adams, becomes slightly positive. The directive influence of light was tested by PARKER and ARKIN and by ADAMS by placing the worm at right angles to the direction of the rays and noting the number of times it extended its head towards or away from the

\footnotetext{
IHomeistek, W. Die bis jetzt bekannten Arten ausder Familie der Regenwürmer, Braunschuei,s, $1 \$_{45}$.

${ }^{2}$ Daxwis, C. The Formation of Vegetable Mould through the Action of Worms, with Observations of their Ilabits, New York, 1900.

GGraber, V. Grundlinien zur Erforschung des Helligskeits und Farbensinnes der Thiere, Litipaig, I884.

"Yung, E. Compt. Rent. Traz. Sor. Heli. Sci. Nat. 1892, p. 127.

${ }^{5}$ Hesse, R. Ziit. iviss. Zool. $1896,61,393$.

BPARKER and ARKIN. Am. Jour. Fhysiol. 190I, 4, $15 \mathrm{I}$.

'Sмітн, A. C. Am. Jour. Physiol., 6, 459.

${ }^{8}$ Andms, G. P. Am. Jour. Ihysiol., 9, 26.
} 


\section{Journal of Comparative Neurology and Psychology.}

light, or simply straight ahead. In all except very weak light the number of negative reactions was found to exceed the positive ones, the proportion being greater, as a rule, the more intense the illumination (ADAms). In these investigations attention was nainly centered upon the direction of the response, the directive influence of light falling on different regions of the body, and the effect of light of different intensities. The mechism of the reaction was not especially considered.

If the earthworm is more likely to turn away from the light than towards it, it might be concluded that the light exercises a direct orienting effect upon its movements, but this does not necessarily follow. When exposed to a very strong light (the beam of a projection lantern passed through an alum cell was used) the earthworms experimented with showed the following type of reaction. The light in the first place stimulates the animal to activity, calling forth the regular movements of locomotion. Waves of contraction of the circular muscles pass from behind forward; the anterior end of the body is extended and set down; waves of contraction of the longitudinal muscles follow those of the circular ones and pull the posterior part of the body forward. As the worm crawls it trequently moves the head from side to side as if feeling its own way along. If a strong light is held in front of the worm it at first responds by a vigorous contraction of the anterior part of the body; it then swings the head from side to side, or draws it back and forth several times, and extends again. If in so doing it encounters a strong stimulus from the light a second time it draws back and tries once more. If it turns away from the light and then extends the head it may follow this up by the regular movements of locomotion. As the worm extends the head in crawling it moves it about from side to side, and if it happens to turn it towards the light it usually withdraws it and bends in a different direction. If it bends away from the light and extends, movements of locomotion follow which bring the animal farther away from the source of stimulus.

The experiments of PrkKER and ARkin show that the head of the worm in crawling is more apt to turn away from the light 
as it extends than towards it. It is probable, although not expressly stated, that account was taken of the first decided turn that was made. If one watches carefully the movements of a worm that is placed at right angles to a strong beam of light it will be seen that the head frequently moves from side to side before extension takes place. These movements may be very slight and ordinarily would escape attention. There is often a similar movement during the process of extention. Frequently the head is bent over towards the light during the first part of the extension and then bent the other way and extended farther, or again it may be waved back and forth several times. Slight trial movements in all directions are continually being made. The reason why the worm makes more turns of a dicided sort away from the light than towards it is largely because the little trials that bring the worm nearer the light are not followed up. Many of the turnings that would naturally be counted as negative are preceded by a slight positive turn followed by a stronger negative one. In order to ascertain whether the negative reaction was manifested at the very beginning of the response the following experiment was tried. A worm was allowed to crawl on a wet board. When it was crawling in a straight line it was quickly lowered into the beam from a projection lantern so that its body would lie at right angles to the rays. The exposure to the light was made in each case when the worm was contracted, and the first detectible movement of the head to one side noted. In the two specimens employed the first detectible turn was away from the light 27 times and towards the light 23 times. After a few extensions the worm in nearly all cases soon turned and crawled away from the light. The first detectible movement of the earthworm seems, therefore, to be nearly as likely to be towards the light as away from it. The slight preponderance of negative turns may be due to the fact that some of the smaller trial movements were overlooked, to a slight direct orienting effect of the rays, or merely to chance. A decided turning such as was probably counted in PAkKer and Akkin's experiments may represent a first trial, or a result of perhaps several very small trials. It is easy to 


\section{IO2 Journal of Comparative Neurology and Psychology.}

see that in strong illumination extensions towards the light are checked while those that bring the worm away are followed up, but this is not so obvious in light of weaker intensity. Whether the negative reaction takes place entirely by the selection of random movements is hard to determine with certainty, but there is no doubt that this factor plays a very large part in the process.

Experiments performed by Miss Rrouss and myself three years ago upon the phototaxis of leeches showed that the method of orientation in these forms is, in principle, the same as that of the earthworm. When specimens of Glossiphonia are placed in strong light their locomotor reflexes are set in action. The mode of progression in Glossiphonia differs from that of the earthworm, altlough in certain fundamental respects the same. The anterior part of the body is extended, the mouth which acts as a sucker is attached, and then the posterior part of the body is brought forward and fastened by the sucker at its caudalend. Then the anterior part of the body extends again and the other movements follow as before. In its progress the leech frequently raises the extended anterior part of the body and waves it from side to side as if feeling its way. If the animal turns it in the direction of a strong liglut it is quickly withdrawn and extended again, usually in another direction. If the light is less strong it waves its head back and forth several times and sets it down away from the light; then the caudal end is brought forward, the anterior end extended and swayed about and set down still farther from the light than before. When the leech becomes negatively oriented it may crawl away from the light, like the earthworm, in a nearly straight line. The extension, withdrawal and swaying about of the anterior part of the body erable the animal to locate the direction of least stimulation, and when that is found it begins its regular movements of locomotion. Of a number of random movements in all directions only those are followed up which bring the animal out of the the undesirable situation.

The phototactic reactions of the larvæ of the Muscidce have 
been studied by Dr. LOEB ${ }^{1}$ who found that these forms travel away from the light approximately in the direction of the rays. If an object was held so as to cast a shadow close to their line of locomotion the larvæ would crawl close to the margin of the shadow almost directly away from the light. LOEB remarks upon the significant fact that the oral end of these larvæ is the region of especial sensitiveness. Larvæ which crawled out of the shadow into the direct sunlight were often found to respond vig. orously as soon as the anterior half or third of the body was exposed to the stronger illumination. "Das Thier hemmte seine Bewegung und bog den Kopf um, ca. 90- I $30^{\circ}$ nach rechts und links. Kam dabei die Spitze des Kopfes wieder in den Schatten, so kehrte das Thier in den Schatten zurück. Geschah das aber, wie es meist der Fall war, nicht, so setzte das Thier seine Bewegung in das Sonnenlicht fort. Die Hemmung der Bewegung aber beim Uebergang aus dem Schatten in die Sonne war keine allgemeine Ërscheinung. Meist gingen die Thiere ohne Versögerung aus dem Schatten in die Sonne. Dass die Lichtstrahlen, weche den Kopf treffen, wesenlich massgebend fur die Orientirung sind, geht aus folgender Beobachtung hervor: Hatte ich ein ausgewachsenes Thier auf einem Brett und schob ich das letztere so aus dem Schatten in die Sonne, dass nur der Kopf des Thieres von Sonnenlichte getroffen wurde, so stellte das Thier sofort seine Medianebene in die Richtung der Sonnenstrahlen. Brachte ich den aboralen Pol allein in's Sonnenlicht, so trat diese Orientirung nicht ein. Thiere, denen ich die vordersten Segmente am oralen Pol abgeschnitten hatte, führten auch keine Orientirungsbewegungen mehr gegen Licht aus. Auf solche vivisectorische Versuche indessen, die die Hemmung einer Reizwirkung zur Folge haben, ist wenig Gewicht ze legen" ( l. c. p. 7 I ). I have repeated the experiment of cutting off the heads of the larvæ but found that so much of the soft contents of the body flowed out after this operation that the larvæ made only indefinite movements and soon died, so the experiment threw no light upon the problem.

${ }^{1}$ LoEB J. Der Heliotropismus der Thiere und seine Uebereinstimmung mit dem Heliotropismus der Pfianzen, Würzburg, 1890 . 
104 Journal of Comparative Neurology and Psychology.

Dr. Loeb does not discuss just how the rays of light orient the body of the fly larvæ, so we are left to suppose that he would adopt the same theory of orientation in this case that he has applied to other forms, although from his account of the movements of these larvæ it would almost seem that he had in mind the method of orientation that we have found to be followed by the angleworm and leech. Observations which I have made upon the phototaxis of blow-fly larva with the problem of orientation especially in mind soon convinced me that the movements of these. forms are directed by light through following up those random movements which bring them away from the stimulus. In normal locomotion the fly larva raises the anterior third of its body, extends it and places it down upon the surface to which it adheres; then the posterior end of the body is pulled up, and the anterior end extended again, and so on. At each contraction the ventral part of the posterior portion of the body is brought forward more than the dorsal and is held in place by means of small projections on the surface while the anterior end is being extended, thus giving the larva a forward im. petus. Successive waves of contraction pass from the posterior end and as they reach the anterior part of the body they extend it at the same time that it is raised. The locomotion is a sort of combination of ordinary vermicular movements and the looping movement which is found in the crawling of the larva of the geometrid moths. As the larva progresses the anterior part of the body is often swayed from side to side. When the head is put down, say to the right. the rest of the body is pulled along in the same direction. The source of progressive locomotion is mainly in the posterior half of the body, the anterior portion being used mainly to set the direction of movement.

When strong light is thrown on a fly larva from in front, the anterior end of the creature is drawn back, turned towards one side, and extended again. Often the head is moved back and forth several times before it is set down. Then it may set the head down when it is turned away from the light and pull the body around. If the head in moving to and fro comes into strong light it is often retracted and then extended again in some 
other direction, or it may be swung back without being withdrawn. If a strong light is thrown upon a larva from one side it may swing the head either towards or away from the light. If the head is swung towards the light, it may be withdrawn or flexed in the opposite direction, or, more rarely, moved towards the light still more. If it is turned away from the light the larva usually follows up the movement by locomotion. Frequently the larva deviates considerably from a straight path, but as it continually throws the anterior end of the body about and most frequently follows up the movement which brings it away from the stimulus, its general direction of locomotion is away from the light. In very strong illumination the extension of the anterior part of the body away from the light is followed by a retraction, since in whatever direction it may extend it receives a strong stimulus and the larva writhes about helplessly for some time. Sooner or later. however, it follows up the right movement. Occasionally the larva may crawl for some distance directly towards the light, but after a time its movements carry it in the opposite direction. When once oriented the direction of locomotion of the larvæ is comparatively straight.

In the animals here described there is, so far I can discover, no forced orientation brought about by the unequal stimulation of the two sides of the body, but an orientation is produced indirectly by following up those chance movements which bring respite from the stimulus. I do not deny that there may be an orientating tendency of the usual kind, but if there is it plays only a subordinate rôle in directing the movements of the animal. The orientation of these forms is essentially a selection of favorable chance variations of action and following them up. It is a type of reaction differing from photataxis in its typical form. It does not come under the head of photopathy and it differs from JENNINGS' "motor reflex" by which many of the so-called tropic reactions are producted in the Protozoa, although in common with the two latter modes of response it may be considered as a form of "selection of over-produced movements." The light reactions of the forms studied may be inter- 


\section{Journal of Comparative Neurology and Psychology.}

preted as a resultant of two motor responses; first, the activities of locomotion which are set up by the stimulus of the light, and second, the act of jerking back and bending the body from side in response to a strong stimulus from in front. Here are two instincts or reflexes, however we may be pleased to call them, which are in a measure antagonistic in that the first is frequently overcome by the second. The direction of the external stimulus determines which of these two instinctive tendencies pre. dominates. We do not need to assume that the animal consciously selects and follows up the movements that bring it out of a disagreeable situation, and we need not assume that any association is established between stimulus and reaction, even of the most flecting sort. I do not wish to state dogmatically that such an association is never formed in these organisms, since observations on other forms lead me to speak guardedly on this point; but it cannot, I believe, be more than a minor factor in their phototactic response, if it exists, In so far as the effect of previous experience is not involved, the type of reaction in question differs from the trial and error method of primitive animal intelligence. At the same time, it resembles that method in that a multitude of movements are made of which only certain ones are followed up. It may be said to be a form of the trial and error method minus the element of learning by experience.

The type of reaction we have described is one which is very widespread among the lower animals, and it doubtless enters as one element into many of the tropic reactions which we commonly explain as the result of forced reflexes. The element of spontaneous, undirected activity is one of vast if not essential importance in the life of nearly all animals. The simpler animals profit by their varied experience, although they may not learn, and thus secure some of the advantages which it is generally considered the special function of intelligence to confer.

In a valuable paper which appeared after the preceding portion of this article was written Dr. JenNings' ${ }^{1}$ points out the

'JENNINGS, H. S. Contributions to the Study of the Behavior of Lower Organisms, Washington, 1904. 
important role played by the method of trial and error in the behavior of the lower organisms, especially the protozoa. In the work that has been done on the instincts and reactions of animals in recent years too much stress has doubtless been laid upon the action of the environment on the organism and too little upon the internally initiated actions of the organism itself. Animals are frequently regarded as if they were more or less passive instruments played upon by external agencies and responding in the right way because they are so constructed that they cannot do otherwise. Rather, they are like instruments running by their own inherent energy, like a music box that is wound up and so regulated as to produce a variety of melodies. External agencies press the stops here and there and change the tune. If one tune does not suit, the environment is heard from and the instrument shifts to another.

The method of trial and error in its widest sense is one of those very large categories under which a multitude of varied activities may be subsumed. Even the process of natural selection may be considered a form of it, since all variations may be regarded as trials, and the unsuccessful ones errors. By a little squeezing we might also include many of the phenomena of development and regeneration. In psychology it is comnionly recognized not only as the method of primitive animal intelligence, but as forming an essential element of the process of reasoning in its more abstract forms. Now it is coming to be read back into the realm of instinct and tropisms. In all these fields it is, par excellence, the method of adaptation. Instinctive behavior is either a direct expression of it, or, so far as instincts are stereotyped, indirectly the outcome of it through the principle of natural selection.

The rôle played by the trial and error method in the behavior of the lower organisms has, as yet, elicited but little comment, owing probably to the fact that attention has been centered more upon other features of their behavior. It may have been considered by some investigators as too obvious for remark since anyone who attentively observes the conduct of almost any of the lower animals for ten minutes can scarcely 
Io8 Journal of Comparative Neurology and Psychology.

fail to see the method exemplified. If he were watching a chick pecking at a variety of objects and giving signs of disgust when it had seized a nauseous substance he would doubtless regard the process as one of trial and error whatever name he might apply to it. A study of the conduct of much lower organisms would disclose many cases almost equally evident. The lives of most insects, crustaceans, worms, and hosts of lower invertebrate forms including even the protozoa show an amount of busy exploration that in many cases far exceeds that made by any higher animal. Throughout the animal kingdom there is obedience to the Pauline injunction, "Prove all things; hold fast that which is good."

The trial and error method is set off by JeNnINGs in sharp contrast to the usual scheme of tropic reaction. "The tropism," he says, "leads nowhere; it is a fixed, final thing, like a crystai." And elsewhere: "This method of trial and error, which forms the most essential feature of the behavior of these lower organisms, is in complete contrast with the tropism schema, which has long been supposed to express the essential characteristics of their behavior. The tropism was conceived as a fixed way of acting, forced upon the organism by the direct action of external agents upon its motor organs. There was no trial of the conditions; no indication of anything like what we call choice in the higher organism; the behavior was stereotyped." (p. 250). If the term trial and error is used in the wide sense here employed I cannot but think that the distinction between the method so designated and the orthodox scheme of tropisms is not, after all, so wide as it at first appears. The motor reaction of Paranecium is certainly a fixed way of acting brought about almost inevitably by certain factors of the environment. Its behavior is certainly as stereotyped as that of any organism whose reactions are definitely known. Its reactions are "forced movements" in the untechnical sense of this expression, and there is no more evidence of choice in its conduct than in the contraction of a muscle; for we can scarcely speak of choice in a creature that reacts in one way to all sorts of stimuli. On the other hand the trial and error method may be ex- 
tended to cover the reactions of an animal which orients itself according to the usual scheme. If an earthworm when illuminated more on one side of the body than another simply turned away, by a direct reflex, from the greater stimulus and kept on doing so until the body was brought parallel with the rays we would have a case of orientation according to the commonly accepted theory of tropisms. The creature is forced into line by unequal stimulation of the two sides of its body. When in crawling one side of the body comes to be presented to the light more than the other deviation is corrected by a direct movement away from the stimulus. Getting out of line may be regarded as an error which brings about a certain reflex that sets the animal again upon a straight course. The worm keeps in an approximately straight path because those movements (errors) which bring it out of a straight course are counteracted by a definite reflex, while those movements (successful trials) which bring the creature away from the light are followed up. It is because these errors are corrected that the orientation even according to the ordinary theory, is maintained. These deviations are as much errors as the random movements towards the light in the method of orientation that is actually followed.

The stimuli in ordinary tropisms may, however, serve to prevent errors as well as to correct them after they are made. Take an organism that orients itself by the direct method. As it swings out of line it is doing so against the influence of the unilateral stimulus which tends to turn it back during, as well as after, the trial. But the mechanism of preventing the movement and of reversing after it is made is, in this case, the same; only in proportion as the checking predominates does the random character of the movements becomes reduced. Between the behavior of an organism like an earthworm that jerks back and turns to one side when the anterior end is stimulated and that of one which turns directly when the side is presented to the stimulus there is to be sure a maked difference in behavior, but there is an underlying basis of similarity in the two cases in that in both errors are made, although they are corrected in different ways. The end result of both methods is the same, i. e. 


\section{Journal of Comparative Neurology and Psychology.}

to get the organism away from the stimulus. In the one case it is accomplished by a direct reflex, without more ado; in the other only after a considerable waste of energy in inconsequential vermiculations. In orientation according to the usual theory of tropisms errors are made in abundance; but they are corrected in a more direct and efficient way than in the more or less haphazard method so frequently followed.

By a careful analysis of the phototaxis of Stentor, Euglena, and some other protozoans Jensixgs has concluced that the oritation of these forms to light takes place according to the trial and crror method, and not by the method of simple forced reflexes. The reactions of Euglena are of especial interest since this form apparently shows a combination of both direct and indirect methods of orientation to the direction of the rays. Fisglena may react to a strong or sudden stimulus from the light by backing off and starting ahead in a new direction. Several trials of this kind may be made until finally the creature becomes oriented when it swims to or from the light according to the intensity of the stimulus. Euglena is also capable of orienting itself by gradually bending its course until it comes to be approximately parallel with the rays. Ordinarily this form swims in a straight spiral path. Should light shine on the body from one side the sensitive anterior end would be stimulated differently in different parts of its spiral course. According to Jexisugs, it is the diminution of light as the animal turns the anterior end away from the stimulus that causes the motor response. When the Euglena turns so that the anterior end is less illuminated, it is stimulated to swerve back further towards the light, and, by a succession of such responses, it finally becomes orieuted to the dircction of the rays. Swimming through that portion of its spiral course that causes the diminution of light at the anterior end is that part of the creatures activities that must be looked upon as error, if we go so far as to regard the pasing through different sections of a continuous spiral course as trials. But to view the matter in this way is to go far towards obliterating the distinction between orientation through trial and error and orientation by the direct method. In the mode of photo- 
tactic response here considered Euglena does not react by a number of indiscriminate movements until the right one is accidentally hit upon, but by a direct reflex whose effect is to bring the organism more nearly parallel to the direction of the rays. The phototaxis of Euglena is not so manifestly the outcome of the trial and error method as that of the earthworm. In the latter case light does not cause directly a movement which makes for orientation. The direct response may or may not have that effect. The successful movement is accidentally hit upon, but one can scarcely say this in the case of Euglona in which the orientation takes place more nearly in accordance with the usual scheme.

It is perhaps difficult to decide where best to draw the line as regards the employment of the expression trial and error. If it is extended to include the phototaxis of Euglena and other protozoa where there is a gradual adjustment of the path by appropriate direct responses until it coincides with the direction of the rays, we can hardly stop short of including, at least to a considerable degree, the cases of phototaxis that take place according to the commonly accepted theory. We may regard all departures from the straight and narrow path as errors according to whatever theory of phototaxis we may choose to adopt, and we can look upon all movements in that path as successful experiments. I would suggest that if the term trial and error is widened, as seems desirable, so as to include such reactions as are described in the first part of this paper where there is no discernible element of learning involved, its application be limited to those cases in which the adapted movements may be regarded as chance successes. This would exclude the tropisms of the orthodox kind; it would exclude the gradual orientation of such forms as Euglena where oblique stimulation causes a direct response which brings the body more nearly parallel to the rays. It would include many of the reactions of the protozoa where, as in the phototaxis of the blue Stentor, the right direction of movement is hit upon by chance, and a large part of the actions of higher forms. All organisms make errors. In some cases these errors are rectified by an appropriate direct reflex, 
112 Journal of Comparative Neurology and Psychology.

in others by the chance success of a random movement. There will doubtless occur many cases difficult to classify where trials are not perfectly random movements but where the stimulus may have a certain directive effect which is in large measure obscured. A tropism of the direct sort is not necessarily a perfectly fixed and rigid affair. It may be a tendency more or les obscured by a lot of random movements arising from internal causes. An organism may be drawn to a certain point through a direct orienting reflex, but if there be at the same time a large element of random activity in its behavior it may seem to reach that point by the method of trial and error. In the trial and error method the random character of the movements impresses us most; in the tropisms, the element of direct determination by the environment. Both of these factors run through the behavior of all animals, but they are mingled in various proportions in different forms. In the lives of most, if not all, animals both are essential elements in the adjustment of the organism to its conditions of existence.

(niversity of Michiran, Ann Arbor, Mich. Dec. 6, 1904. 